\title{
Immune-to-detuning Wireless In-body Platform for Versatile Biotelemetry Applications
}

\author{
Denys Nikolayev, Member, IEEE, Maxim Zhadobov, Senior Member, IEEE, and Ronan Sauleau, Fellow, IEEE
}

\begin{abstract}
Background and Objective: In-body biotelemetry devices enable wireless monitoring of a wide range of physiological parameters. These devices rely on antennas to interface with external receivers, yet existing systems suffer from impedance detuning caused by the substantial differences in electromagnetic properties among various tissues. In this paper, we propose an immune-to-detuning in-body biotelemetry platform featuring a novel tissue-independent antenna design. Methods: Our approach uses a novel slot-patch conformal antenna integrated into a flexible polyimide PCB containing the device circuitry and encapsulated within a $17.7 \mathrm{~mm} \times \varnothing 8.9 \mathrm{~mm}$ biocompatible shell. The antenna is synthesized and optimized using a hybrid analytical-numerical approach, then characterized numerically and experimentally in terms of impedance stability. Results: The proposed platform shows stable impedance whereas operating in any mammalian tissue as well as in air. The system is optimized for the $434 \mathrm{MHz}$ ISM band and can easily be returned for any MedRadio band in the 401-457 MHz spectrum. Conclusion: Ultra-robust impedance characteristics were achieved. Without any modifications, the proposed biotelemetry platform can be used, for instance, as an ingestible for humans or as an implantable for a wide range of animals: from rodents to cattle.
\end{abstract}

Index Terms-biomedical telemetry, conformal antennas, implantable, in-body, ingestible, ISM (industrial, scientific, and medical) band, MedRadio band, robust antennas.

\section{INTRODUCTION}

$\mathbf{I}$ NGESTIBLE and implantable (in-body) devices for biomedical telemetry (Fig. 1) provide powerful capabilities in medicine, clinical research, sports, and occupational health [1]-[4]. In-body devices allow for continuous monitoring of various physiological parameters, namely intracorporal temperature, pressure, $\mathrm{pH}$, glucose, hormone, antibody levels, endoscopic imagery, and so on. Moreover, implantable devices are a promising platform for therapeutic actuation using instrumented active implants [5], neural stimulators [6], and so on.

In-body biotelemetry devices rely on radiofrequency (RF) antennas to interface with external systems. The antenna

Manuscript received September 13, 2018; revised December 3, 2018; accepted January 1, 2019. This work was supported in part by the BodyCap Company, in part by the French National Center for Scientific Research and Directorate General of Armaments through the PEPS program, in part by Rennes Metropole through the AES program, and in part by the French Ministry of Foreign Affairs and International Development through the Eiffel Scholarship. (Corresponding author: Denys Nikolayev.)

D. Nikolayev is with the Imec / Ghent University, 9052 Gent, Belgium and also with the Institute of Electronics and Telecommunications of Rennes, UMR CNRS 6164, University of Rennes 1, 35042 Rennes, France (e-mail: $\mathrm{d} @$ deniq.com)

M. Zhadobov and R. Sauleau are with the Institute of Electronics and Telecommunications of Rennes, UMR CNRS 6164, University of Rennes 1, 35042 Rennes, France.

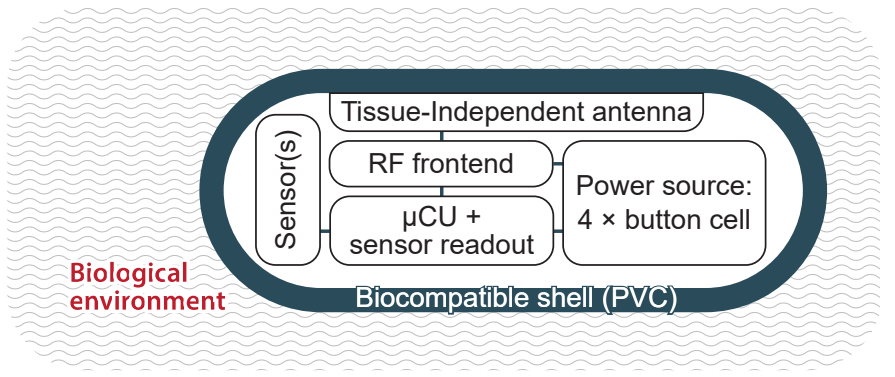

Fig. 1. Outline of the wireless pill-shaped device for biotelemetry. Tissueindependent antenna design ensures the detuning immunity.

performance strongly depends on dispersive electromagnetic (EM) properties $\hat{\varepsilon}(\omega)=\varepsilon^{\prime}(\omega)+j \varepsilon^{\prime \prime}(\omega)$ of surrounding tissues [8], where $\varepsilon^{\prime}$ is the real part of the permittivity, $\varepsilon^{\prime \prime}$ is the imaginary part of the permittivity, and $\omega$ is the angular frequency. The radiated wave undergoes attenuation due to tissue losses (characterized by $\varepsilon^{\prime \prime}=\sigma / \omega$, were $\sigma$ is the conductivity) and scattering because of tissue heterogeneity $\hat{\varepsilon}(\mathbf{r}, \omega)$ [9]. Another factor limiting the antenna performance is its impedance $Z_{A}(\hat{\varepsilon}, \omega)$ detuning caused by varying EM properties $\hat{\varepsilon}(\mathbf{r}, \omega)$ of biological tissues (Table I) [10]. The wider is the range of tissue EM properties that the antenna can handle (i.e. matching remains below $\left|S_{11}\right| \leq-10 \mathrm{~dB}$ ), the more it is considered robust.

Designing an in-body device that can operate from any tissue (i.e. ultra-robust) allows for its application in a wide range of scenarios. For instance, the same wireless temperaturetelemetry capsule (e.g. BodyCap e-Celsuis [11]) can be used as an ingestible for humans and as an implantable for animals that can range in size from a mouse to a cow. In addition, advanced activation circuits make it possible to develop autonomous devices with ability to deliver therapeutic actuation [7].

The majority of existing in-body capsule antennas are designed for a specific ap p lication (i n gestible, subcutaneous, osseous, and so on) [12]-[19], whereas the robustness is ensured only within a target application. For ingestible applications, this includes analyzing the antenna performance in stomach, small intestine, and colon (Table I). Magill et al. [20] proposed a $2.45 \mathrm{GHz}$ tissue-independent antenna that shows good matching in all high-water-content tissues $\left(\left|S_{11}\right|<\right.$ $-10 \mathrm{~dB})$ as well as in fat $\left(\left|S_{11}\right| \approx-7.5 \mathrm{~dB}\right)$. Yet, the existing robust designs rely on thick high-permittivity ceramic substrates and superstrates, thus making them inapplicable for capsule-conformal applications. A robust capsule-conformal 
TABLE I

ELECTROMAGNETIC PROPERTIES OF DIFFERENT TISSUES AND ORGANS AT $434 \mathrm{MHz} \mathrm{[10]}$

\begin{tabular}{lcc} 
Tissue & Rel. permittivity $\varepsilon_{r}$ & Conductivity $\sigma\left(\mathrm{S} \cdot \mathrm{m}^{-1}\right)$ \\
\hline Bone (cortical) & 13.1 & 0.09 \\
Fat (not infiltrated) & 5.6 & 0.04 \\
Grey matter & 56.8 & 0.75 \\
Kidney & 65.4 & 1.12 \\
Large intestine & 62.0 & 0.87 \\
Muscle & 56.9 & 0.81 \\
Small intestine & 65.3 & 1.92 \\
Stomach & 67.2 & 1.01 \\
Thyroid gland & 61.3 & 0.89 \\
\hline
\end{tabular}

microstrip antenna has been proposed in [21]. However, it detunes in fat $\left(\left|S_{11}\right| \approx-3 \mathrm{~dB}\right)$ and requires costly ceramic superstrate. Moreover, as in-body devices move into mass production and their shells get thinner to increase the available space inside of the device, ensuring robustness on the antenna level is highly desired.

Here, we propose an immune-to-detuning in-body platform based on an ultra-robust antenna that has a potential to operate from any mammalian tissue as well as in air. The latter makes it possible to communicate with the device prior to its ingestion or implantation. In addition, it ensures the operation in respiratory system, for instance.

The paper is organized as follows. Section II starts by theoretical considerations, then it describes the choice of materials and the ultra-robust antenna synthesis approach. Section III deals with the numerical analysis, and Section IV provides the experimental validation. Conclusions are drawn in Section VI.

\section{WiRELESS IN-BOdY Platform DESIGN}

\section{A. Theoretical Considerations}

First, we defined the operating frequency according to prior theoretical studies [9], [22], [23]. The optimal frequency range (i.e. where the radiation efficiency is on its peak) depends, among others, on the depths of the antenna in a body. Generally, the closer the antenna is to the surface, the higher the optimal frequency. Considering both deep-body and subcutaneous applications, we chose to design the antenna for the $434 \mathrm{MHz}$ ISM (Industrial, Scientific, and Medical) band [24]. As shown ahead in Section III-B, an adjustment can retune the antenna to any MedRadio (Medical Device Radiocommunications Service) band as well [25].

To be ultra-robust, the antenna must be insensitive to its environment-in other words, remain matched with $\left|S_{11}\right|<$ $-10 \mathrm{~dB}$ at the operating frequency $f_{0}$. The environment consists of biological tissues having a wide range of EM properties that, according to Gabriel et al. [10], may vary as $\varepsilon_{r} \in[5.6 . .80], \sigma \in[0 . .2 .4] \mathrm{S} \cdot \mathrm{m}^{-1}$ at $434 \mathrm{MHz}$. The operating environment may also include air for some application scenarios (e.g. in lungs or trachea). Moreover, some in-body devices usually require an activation (in air) prior to implantation or ingestion. In addition, they can be designed to operate in the

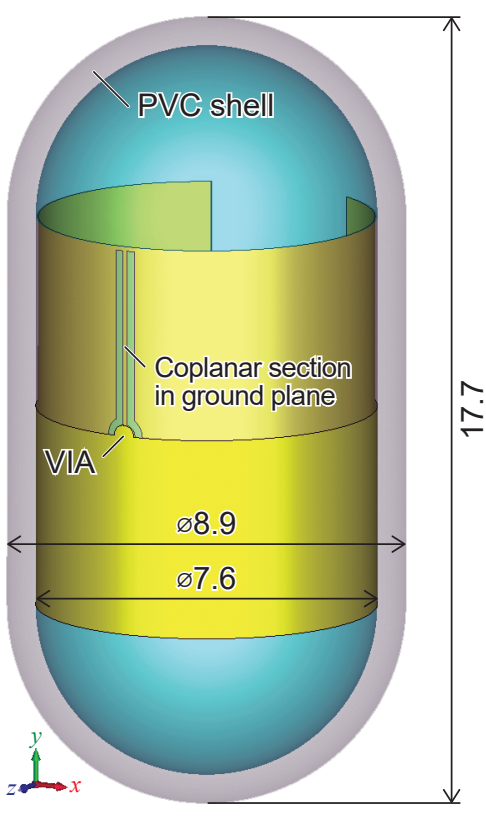

(a)

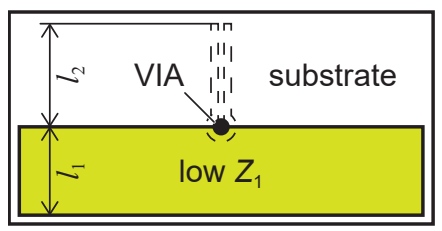

(d)

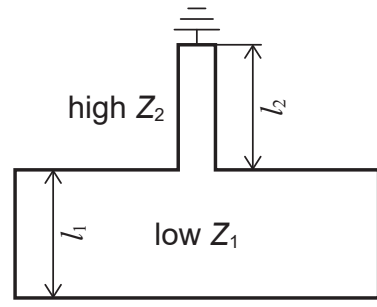

(b)

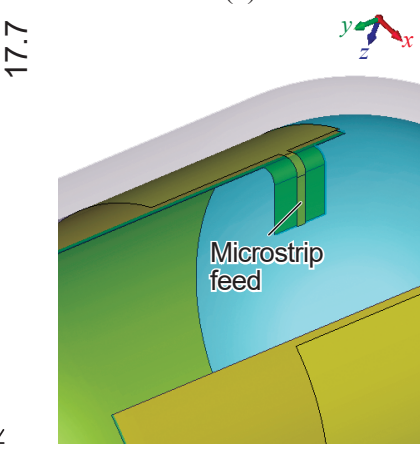

(c)

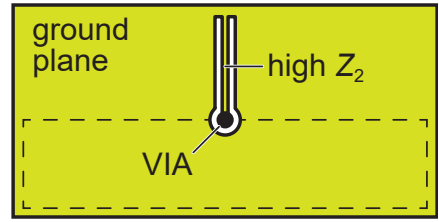

(e)

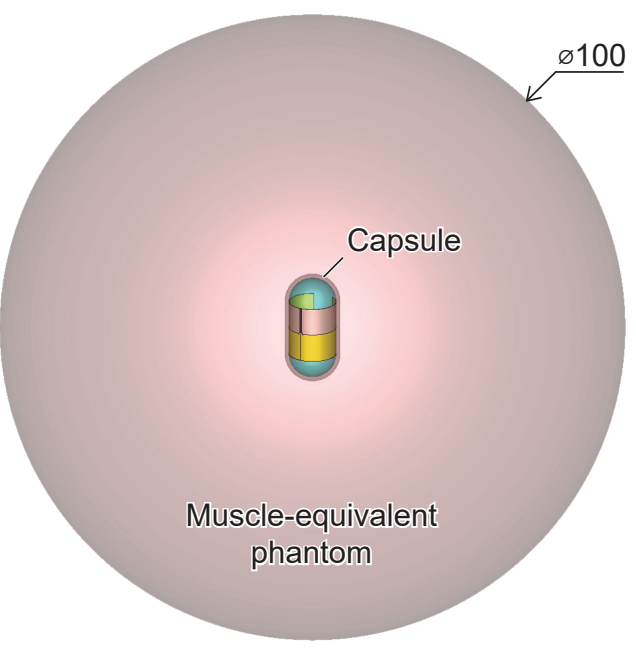

(f)

Fig. 2. Geometry and building blocks of the proposed capsule antenna ( $\mathrm{mm})$. (a) The antenna conforming to the inner surface of a $0.65-\mathrm{mm}$-thick PVC shell. (b) Theoretical representation: a quarter-wave stepped-impedance resonator. (c) Foldable microstrip feed connecting the antenna to the PCB (not shown). (d), (e) Top and bottom views, respectively, of the planar geometry of the antenna $\left(l_{1}=4.5, l_{2}=4.2\right)$. (f) Simulation setup in CST MWS.

respiratory system. Therefore, the range of relative permittivity extends to $\varepsilon_{r} \in[1 . .80]$.

Tissue losses significantly affect the radiation performance of in-body antennas. High-permittivity capsule shells (mostly made of low-loss perovskite-type ceramic materials) mitigate 
the losses in near field [26], [27]. However, high material costs limit the scope of potential applications and make the mass production impossible. Using low-cost materials (usually, lower-permittivity biocompatible plastics) results in stronger antenna coupling to the adjacent lossy tissues. Sections of microstrip antennas with high characteristic impedance (high$Z$ ) are the most affected by this due to broader fringing fields that penetrate into the tissues. This coupling substantially reduces the antenna robustness. Therefore, we conjectured that realizing the high- $Z$ section as a coplanar line in the ground plane of the antenna would move the fringing fields inside of the practically lossless capsule and away from the tissues. This helps reducing the variance of effective EM properties $\operatorname{Var}(\hat{\varepsilon})$ in the near-field zone of the antenna hence results in improved robustness.

The reader is warned that this configuration per se would backfire with reduced radiation efficiency $\eta$ (compared to counterparts) due to, in particular, increased current symmetry and high wave-impedance contrast between the capsule environment and tissues. To partially mitigate these effects, we considered the following. First, as we deal with electrically small antennas (ESA) in lossy media $(k a<0.5$, where $k$ is the wavenumber and $a$ is the antenna circumradius), enlarging the antenna size increases its theoretically achievable radiation efficiency $\eta_{\max } \propto k a / \mathrm{FBW}$ [28], [29], where FBW is the half-power fractional bandwidth. Therefore, we maximized the antenna circumradius $a$ by spanning it along the whole length of a cylindrical section of the capsule (8.8 mm, Fig. 2). Second, filling the capsule with a low-loss material having its relative permittivity $\varepsilon_{r}>1$ loads the antenna and further increases its electrical size $k a$ as $k \propto \sqrt{\varepsilon_{r}}$ [21]. Third, avoiding meandering of the high- $Z$ section (Fig. 2b) may increase the net current on the section and improve the radiation efficiency. Finally, keeping the substrate as thick as possible improves the radiation efficiency as well [30]. The maximum thickness is restricted though by mechanical constraints, as the printedcircuit board (PCB) requires bending and folding. Fig. 2c shows the bending of the microstrip feed in order to reach the RF frontend.

\section{B. Materials and Packaging}

1) Printed Circuit Board: The proposed antenna integrates on the same PCB as the capsule circuitry. In this way, the antenna is patterned in one process with the circuitry thus minimizing manufacturing costs. The copper-clad substrate is made of DuPont ${ }^{\mathrm{TM}}$ Kapton ${ }^{\circledR}$ polyimide film [31] with $\varepsilon_{r}=3.4, \tan \delta=0.002$ and can vary in its thickness from $25.4 \mu \mathrm{m}$ to $152.4 \mu \mathrm{m}$ with a $25.4 \mu \mathrm{m}$ increment. After evaluating the mechanical stress due to folding, the thickness of the substrate was set to $50.8 \mu \mathrm{m}$. Hypothetically, one can improve this design by using a substrate with variable thickness - minimal for the circuitry (that requires folding) and maximal for the antenna (that performs better on a thicker substrate). In practice, this approach substantially increases manufacturing cost that limits the scope of applications of the antenna.
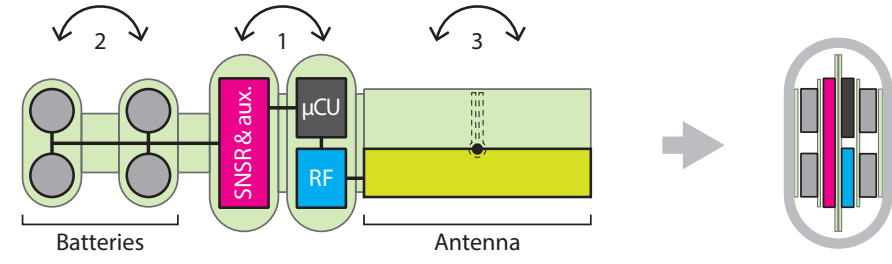

(a)

(b)

Fig. 3. Example of possible packaging. (a) Flexible PCB containing batteries, sensor(s) (SNSR), auxiliary circuits (aux.), microcontroller ( $\mu \mathrm{CU}), \mathrm{RF}$ matching circuit (RF), and the antenna. The numbers indicate folding order. (b) Resulting package.

2) Encapsulation: The antenna conforms to the inner surface of a 0.65 -mm-thick biocompatible capsule shell. The overall dimension of the shell are $17.7 \mathrm{~mm} \times \not 8.9 \mathrm{~mm}$ (Fig. 2a). It is made of PVC with additives to improve mechanical properties; the dielectric properties were initially unknown. In contrast to ceramic shells, the plastic one allows for mass production through low material and process costs. This, however, comes at a price of reduced radiation efficiency.

3) Capsule filling: Filling the capsule with a solid dielectric material helps preserving its structure integrity, increases the electrical size of the antenna, and improves wave-impedance matching with the surrounding tissues. In addition, leveling permittivities of the superstrate and filling reduces the manufacturing tolerance requirements on how tight the antenna has to conform to the superstrate. In this paper, we use a biocompatible bi-component epoxy resin. As for the encapsulation PVC, the dielectric properties were initially unknown.

4) Characterization of materials: To determine dielectric properties of the PVC and the epoxy, we measured its complex permittivity in the 100-MHz-to-6-GHz band using a transmission/reflection method. The bulk materials $(\geq 24 \mathrm{~h}-$ cured epoxy) were milled into the 2-mm-thick washers (ext. $\varnothing 7 \mathrm{~mm} \pm 10 \mu \mathrm{m}$, int. $\varnothing 3.04 \mathrm{~mm} \pm 10 \mu \mathrm{m})$ and fitted within an APC-7 coaxial line that was connected to a vector network analyzer (VNA). After post-processing the results, the measured dielectric properties at $434 \mathrm{MHz}$ are: $\varepsilon_{r}=2.6, \tan \delta=0.003$ for the PVC and $\varepsilon_{r}=3.1, \tan \delta=0.037$ for the epoxy.

5) Packaging: Fig. 3 shows the packaging of the device. The circuitry is folded first, then the batteries are wrapped around the circuitry. The antenna envelops the final assembly. Finally, the PCB is inserted into the capsule (Fig. 3b) and filled with the epoxy. The final device containing the circuitry and batteries weights about $2 \mathrm{~g}$ (measured) that makes it usable for a wide range of implantable and ingestible applications.

\section{Antenna Synthesis}

Integrating a $434-\mathrm{MHz}$ antenna $\left(\lambda_{0} / 2 \approx 34 \mathrm{~cm}\right)$ within an 8.8-mm-long cylindrical section of the capsule (Fig. 2a) requires reducing its length to about $3 \%$ of a conventional patch antenna. Surrounding tissues having high effective relative permittivity $\varepsilon_{r}^{\text {eff }}$ load the antenna. This increases the electrical size of the antenna and therefore reduces the necessary miniaturization up to a factor of $\sqrt{\varepsilon_{r}^{\text {eff }}}$. For further size reduction, we shorted the antenna and intoduced an impedance 
discontinuity [32]. Fig. 2b outlines the theoretical structure of the antenna that consists of two transmission lines $Z_{1}$ and $Z_{2}$ of lengths $l_{1}$ and $l_{2}$, respectively. Neglecting the fields at discontinuities, the transmission-line-impedance equation [33, p. 59] enables straightforward modeling of the antenna. For the structure depicted on Fig. $2 b$, the model becomes (full derivation is given in [34]):

$$
\begin{gathered}
\left\{\begin{array}{l}
-Z_{1}+Z_{2} \tan \left(\beta_{2} l_{2}\right) \tan \left(\beta_{1} l_{1}\right)=0 \\
Z_{2} \tan \left(\beta_{1} l_{1}\right)+Z_{1} \tan \left(\beta_{2} l_{2}\right) \neq 0
\end{array}\right. \\
\beta_{n}=\frac{2 \pi}{c} f_{\text {res }} \sqrt{\varepsilon_{r, n}^{\text {eff }}}, \quad n=1,2
\end{gathered}
$$

where $Z_{n}(n=1,2)$ are the characteristic impedances of each section, $\beta_{n}$ are the phase constants, $l_{n}$ are the section lengths, $c$ is the speed of light in vacuum, and $\varepsilon_{r, n}^{\mathrm{eff}}$ are the effective relative permittivities of media surrounding each section.

Characteristic impedances $Z_{n}$ along with corresponding $\varepsilon_{r, n}^{\mathrm{eff}}$ can be evaluated numerically [35] on 2D cross-sections of each line taking into account the effects of both antenna conformability and dielectric loading [36]. Fig. 2d illustrates the microstrip low- $Z_{1}$ element patterned on the PCB top layer, and Fig. 2e depicts the coplanar high- $Z_{2}$ element etched from the bottom layer. The elements couple by means of a via.

To synthesize the antenna, we began by reducing the solution space of (1) by applying the following constrains: 1) $l_{1}+l_{2}=$ const. as the antenna has to span all available space within the cylindrical part of the capsule; 2) $Z_{1}$ is set to its minimum value by taking all available width of the $\mathrm{PCB}$ extension; and 3) the width of the central conductor of $Z_{2}$ was fixed to $100 \mu \mathrm{m}$. In this way, the antenna fine-tuning reduces to one parametric dimension - the width of the coplanar slots.

A microstrip feed connects the antenna to an RF frontend (Fig. 2c). Taking into account the low characteristic impedance of $Z_{1}$ and its small electrical length, we can connect the feed to the longitudinal edge of $Z_{1}$ without any noticeable effect neither on the input impedance of the antenna nor its polarization purity. The longitudinal configuration relieves the mechanical stress on the substrate compared to the transverse feed proposed in [21].

\section{RF Circuit Design}

The antenna connects to a wireless microcontroller with sensor readout capabilities $(\mu \mathrm{CU})$ via an $\mathrm{RF}$ analog frontend (AFE, Fig. 4d). Taking into account the operating frequency of $434 \mathrm{MHz}$, we chose to use the Si-10XX $\mu \mathrm{CU}$ family because of its small footprint (QFN36 package, $5 \times 6 \mathrm{~mm}^{2}$ ), $13 \mathrm{dBm}$ input power (up to $20 \mathrm{dBm}$ ), and high Rx sensitivity $(-126 \mathrm{dBm})$.

The $\mu \mathrm{CU}$ requires a matching circuit to transform the antenna impedance to a single-ended Tx pin and differential $\mathrm{Rx}_{p} / \mathrm{Rx}_{n}$ pins. As the transformation is required independently of the antenna impedance, there is no need for the design to have $50 \Omega$ at $f_{0}$. After evaluating the antenna impedance numerically (Section III) and validating experimentally (Section IV), we tuned a 7-element matching network with directtie topology. It contains an L-type matching circuit for Tx,

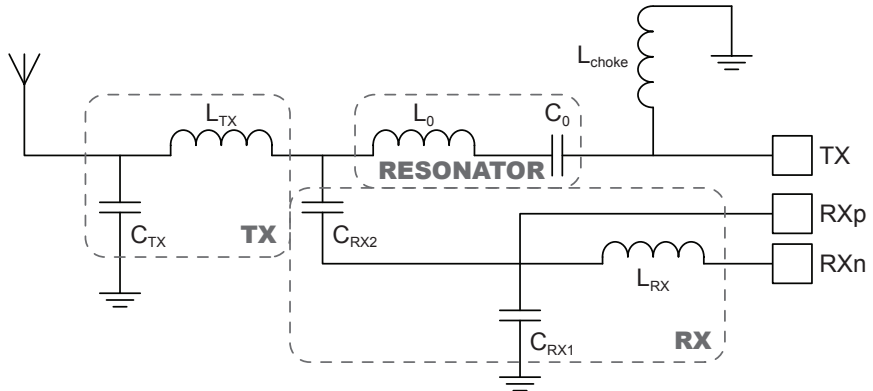

(a)

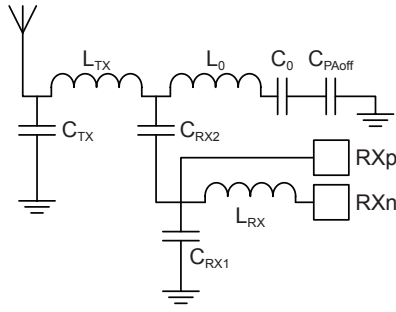

(b)

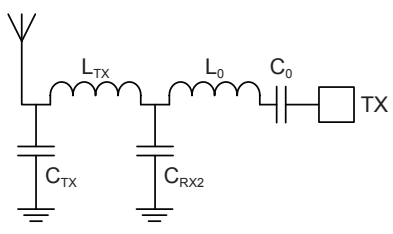

(c)

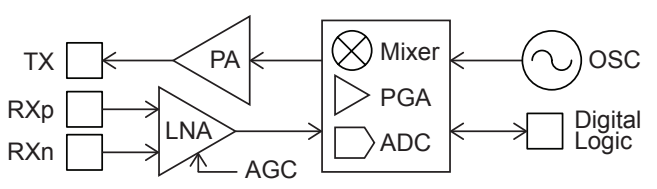

(d)

Fig. 4. (a) Matching circuit direct-tie design containing a resonator, TX and RX branches. (b) Effective circuit in RX and (c) in TX modes. (d) RF AFE topology of Si-10XX $\mu \mathrm{CU}$.

a 3-element $\mathrm{C}_{1}-\mathrm{L}-\mathrm{C}_{2}$ for $\mathrm{Rx}$, and a $434-\mathrm{MHz} \mathrm{LC}$ resonator tank (Fig. 4a). In addition to the conjugate matching, this configuration filters out higher harmonics generated by the power amplifier.

Careful procedure must be followed to calculate the element values ensuring that the RX does not load down the TX output path and vice versa. Fig. 4d shows the RF analog frontend (AFE) of SI 10XX $\mu \mathrm{CU}$. In RX mode, the power amplifier (PA) transistors are turned off, and the load impedance consists mainly of the output capacitance of the transistors $\left(\mathrm{C}_{\mathrm{PAoff}}\right)$. Fig. $4 \mathrm{~b}$ shows the effective circuit. In TX mode, RXp and RXn pins are shorted together and to the ground; the effective circuit is given in Fig. 4c.

The initial values were estimated analytically. The $\mathrm{L}_{0}-\mathrm{C}_{0}$ was set to be parallel-resonant at $434 \mathrm{MHz}$. TX matching $\left(\mathrm{C}_{\mathrm{TX}}\right.$ and $\left.\mathrm{L}_{\mathrm{TX}}\right)$ was calculated using a Smith Chart to transform $Z_{\mathrm{PA}}$ to $\mathrm{Z}_{\mathrm{ANT}}$. $\mathrm{RX}$ matching was calculated analytically to provide a single-ended-to-differential conversion function and to match the low-noise amplifier (LNA) input to $Z_{\mathrm{ANT}}$. The initial circuit showed poor performance due to mutual coupling between TX and RX paths. The final values were estimated using circuit optimization in CST Design Studio. The parameters to optimize were $\mathrm{L}_{0}, \mathrm{~L}_{\mathrm{TX}}$, and $\mathrm{C}_{\mathrm{TX}}$ with the objective functions prioritizing TX: $\left|S_{21}\right|_{\mathrm{TX}}=0 \mathrm{~dB}$ (weight $=$ 2) and $\left|S_{21}\right|_{\mathrm{RX}}=0 \mathrm{~dB}$ (weight $=1$ ). The element parasitics were taken into account as indicated in corresponding datasheets. The resulting transmission coefficients are $\left|S_{21}\right|_{\mathrm{TX}}=$ $-0.06 \mathrm{~dB}$ and $\left|S_{21}\right|_{\mathrm{RX}}=-0.16 \mathrm{~dB}$.

The final capsule prototype contains a thermocouple sensor 
for intracorporal temperature telemetry [37]. The power source is four button cell batteries (Fig. 3).

\section{NUMERICAL ANALYSIS}

After defining the initial geometry using (1), we fine-tuned and analyzed the antenna in CST Microwave Studio 2017 [38] (CST MWS). As the theoretical model takes into account the effects on resonance frequency of both tissue and curvature, we proceeded straight to the capsule-conformal antenna model (Fig. 2a) omitting the planar analysis stage. We used the frequency domain solver of CST MWS (finite element method) as more suitable for resolving the geometry of a low-profile conformal antenna. Adaptive mesh refinement used $\delta\left|S_{11}\right|<$ $1 \%$ for two consecutive passes as a convergence criterion. To improve the mesh quality and thus the convergence, we pre-meshed top and bottom copper layers with $0.1 \mathrm{~mm}$ maxstep width. The copper layers were modeled as thin sheets (impedance boundaries) having $\sigma=5.96 \times 10^{7} \mathrm{~S} \cdot \mathrm{m}^{-1}$. Other EM properties of the antenna materials were set as given in Section II-B.

The proposed antenna is designed to reliably operate from any location within a human or animal body. Therefore, analyzing it in an anatomical phantom is impractical, as one cannot predict all potential implantation sites. Instead, one should use a well-characterized canonical phantom that will make it possible to reproduce the results in measurements. Here, we used the isotropic canonical phantom set-up defined in [39]: the antenna is centered inside of a $\varnothing 100-\mathrm{mm}$ spherical homogeneous phantom with various EM properties depending on the stage of analysis (Fig. 2f). The spherical symmetry conserves the intrinsic radiation pattern of the antenna independently of its orientation.

To maximize the antenna robustness both to the surrounding environment and inner circuitry, we tuned it in the environment with the highest overall EM properties of body tissues [10]. Here, the goal was to cross $\left|S_{11}\right|=-10 \mathrm{~dB}$ level at $434.8 \mathrm{MHz}$ (upper bound of mid-ISM) such that all mid-ISM frequencies would be below $\left|S_{11}\right|<-10 \mathrm{~dB}$ (Fig. 5). In this way, we establish the lowest possible $f_{\text {res }}$, which would shift upwards in all other tissues and in air (as the electrical size of an antenna is proportional to the effective permittivity of its surrounding medium).

\section{A. Antenna Performance and Robustness to Surrounding Media}

Fig. 5 gives the impedance characteristics of the antenna (150- $\Omega$ normalization) when computed in the $\varnothing 100-\mathrm{mm}$ spherical phantom with its EM properties corresponding to various media (Table I). In the muscle-equivalent phantom, $f_{\text {res }}=$ $430.1 \mathrm{MHz}$ and $\mathrm{BW}=11.9 \mathrm{MHz}$ (or FBW=2.8\%). As the antenna is electrically small, it has an omnidirectional radiation pattern (directivity $D=2.14 \mathrm{dBi}$ ). The realized gain is $\max (G)=-34 \mathrm{dBi}$. In fat (the lowest overall EM properties of body tissues, Table I), $f_{\text {res }}=431 \mathrm{MHz}$. As the antenna is resonant, and the EM properties $\left(\varepsilon_{r}, \sigma\right)$ of all remaining body tissues fit within the fat and the overall maximum [10], we can conclude that $\left|S_{11}\right|<-10 \mathrm{~dB} \forall f_{\mathrm{ISM} 434}$ for all body

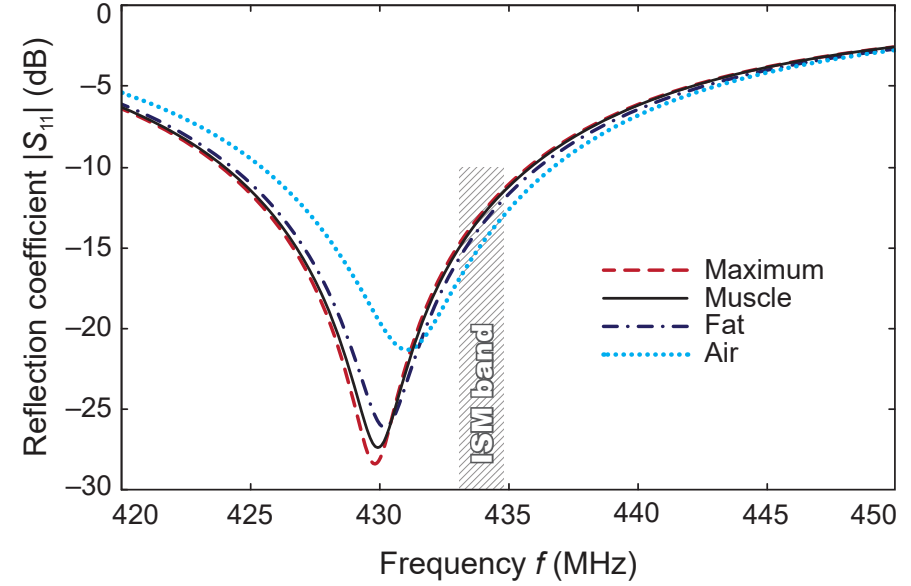

Fig. 5. Reflection coefficient $\left|S_{11}\right|$ of the proposed antenna computed in air and in a $\varnothing 100-\mathrm{mm}$ spherical phantom with various EM properties.

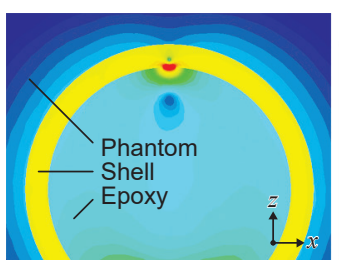

(a)
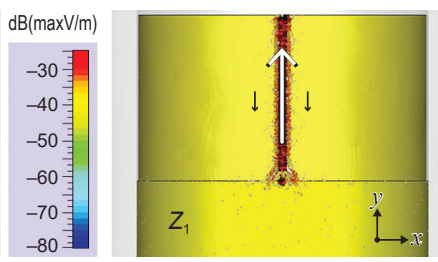

(b)
Fig. 6. Fields of the antenna at $434 \mathrm{MHz}$. (a) $|\mathbf{E}|$-field (dBmax) distribution on the $x-z$ plane orthogonal to $Z_{2}$ section ( $2 \mathrm{~mm}$ from $Z_{1}-Z_{2}$ transition). (b) Surface current distribution $\log (I)\left(\mathrm{A} \cdot \mathrm{m}^{-1}\right)$ for the phase $\varphi=90^{\circ}$.

tissues. In addition, the antenna stays well matched in air, which is, to the best of our knowledge, the first of its kind. The resonant frequencies for all aforementioned media are lower than ISM $434 \mathrm{MHz}$ that allows one compensating for the detuning caused by inner components of the capsule.

Fig. 6a shows the near-field distribution $(|\mathbf{E}|)$ of the antenna around the $Z_{2}$ section. The electric field is enfolded around the central conductor of $Z_{2}$ that helps to concentrate the near field in the capsule shell. This helps to reduce the power dissipation in tissues and to lower the electromagnetic interference with circuitry. In such configuration, the antenna radiates primarily due to non-conserved current and charge in the region of space localized around $Z_{2}$ [40]. Hence, the magnitude of the current in the central conductor of $Z_{2}$ is substantially larger than the one of the opposite current flowing in the ground plane (Fig. 6b).

\section{B. Tuning the Operating Frequency}

The wider the slots of $Z_{2}$ section are, the higher the characteristic impedance $Z_{2}$. According to (1), the resonance frequency of the antenna would decrease as well. This can be used to fine-tune the antenna if the operating frequency must be adjusted within reasonable limits: for instance, to operate in one of MedRadio bands (401-406 MHz, 413$419 \mathrm{MHz}, 426-432 \mathrm{MHz}, 438-444 \mathrm{MHz}$, and 451-457 MHz) [25]. In addition, $f_{\text {res }}$ adjustment may be required if the capsule materials or dimensions change. 
We varied the slot width $w_{s}$ to quantify its effect on the complex antenna impedance $Z_{A}$. The width of the central conductor was fixed to $100 \mu \mathrm{m}$, and $w_{s} \in[50 . .250] \mu \mathrm{m}$. Fig. 7 shows how the resonance frequency depends on $w_{s}$. Within the studied range of widths, the $f_{\text {res }}$ can be tuned to convert the antenna to any MedRadio band [25]. The antenna gain is proportional to $w_{s} ; \max \left[G\left(w_{s}=250\right)\right]=-31 \mathrm{dBi}$ that is $3 \mathrm{dBi}$ higher than for the default width $w_{s}=100 \mu \mathrm{m}$. A cautionary remark: as the radiation resistance of the antenna rises with the radiation efficiency [41], $\Re\left(Z_{A}\right)$ is proportional to $w_{s}$ as well (Fig. 7). An adjustment of a matching circuit of the antenna would be therefore required.

\section{Robustness to Inner Components}

An in-body biotelemetry capsule contains various electronic and biomedical circuits, sensors, and a power source. Up to this point, we have not considered how these inner components may affect the antenna impedance performance. The ground plane partially shields a capsule conformal antenna [21] enhancing its robustness. However, the fringing fields below $Z_{2}$ may couple to the components affecting the antenna impedance. A well-established approach to evaluate the effect of the inner components on the antenna impedance consists in introducing a perfect electric conductor (PEC) cylinder to the capsule model and vary its radius and/or position [13], [15], [21].

As the inner components can vary depending on application, we sought the worst-case scenario of an arrangement that detunes the antenna by: 1) introducing a PEC cylinder of a radius $R_{P}$ spanning the whole length of the antenna $(9 \mathrm{~mm}$, Fig. 2a) and 2) performing a parametric sweep over $R_{P}$ to determine the maximum safe distance $d_{P}$ between the PEC cylinder and the antenna. For $R_{P}<3.3 \mathrm{~mm}\left(d_{P}=450 \mu \mathrm{m}\right)$, no effect on the antenna impedance was observed. As $R_{P}$ increases and the PEC cylinder approaches the antenna, the resonance frequency of the antenna shifts up. Fig. 8 shows how reflection coefficient $\left|S_{11}\right|$ responds to the proximity of the inner components for $R_{P} \geq 3.4 \mathrm{~mm}$. The proposed antenna stays matched below $\left|S_{11}\right|<-10 \mathrm{~dB}$ until $R_{P} \approx 3.5 \mathrm{~mm}$ $\left(d_{P} \approx 250 \mu \mathrm{m}\right)$.

An electric conductor approaching the co-planar section of the antenna reduces its characteristic impedance $Z_{2}$. Indeed, we shall see from (1) that it results in the $f_{\text {res }}$ rising. One can overcome this limitation on $d_{P}$ by stacking bulky components (batteries, for instance) underneath the low- $Z_{1}$ section (Fig. 2d). Here, the ground plane is continuous and fully shields the antenna mitigating the risk of impedance detuning. Therefore, to maintain the antenna impedance, one needs to ensure $d_{P} \geq 250 \mu \mathrm{m}$ around $Z_{2}$ section. In current packaging approach (illustrated in Fig. 3), this is ensured by placing $Z_{2}$ in-between the lobes of the PCB.

\section{Prototyping and Measurements}

Fig. 9 outlines the assembly process of the capsule. The antenna was integrated on the extension of a flexible $50-\mu \mathrm{m}$ thick polyimide PCB (flex) containing the capsule circuitry and batteries (Fig. 9a). Copper layers were patterned using

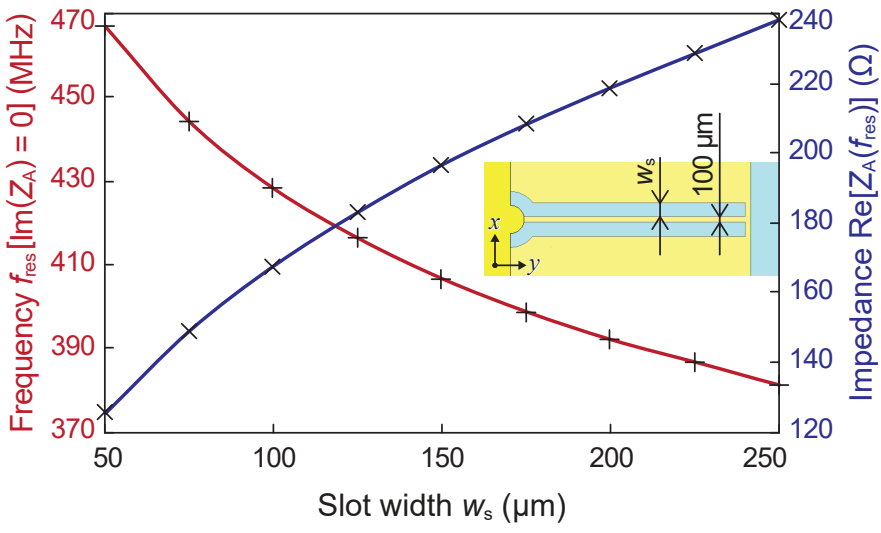

Fig. 7. Adjusting the operating band of the proposed antenna: effect of the coplanar slot width $w_{s}$ on antenna complex impedance $Z_{A}$ (inset shows the geometry of the coplanar segment $Z_{2}, w_{s}=200 \mu \mathrm{m}$ ).

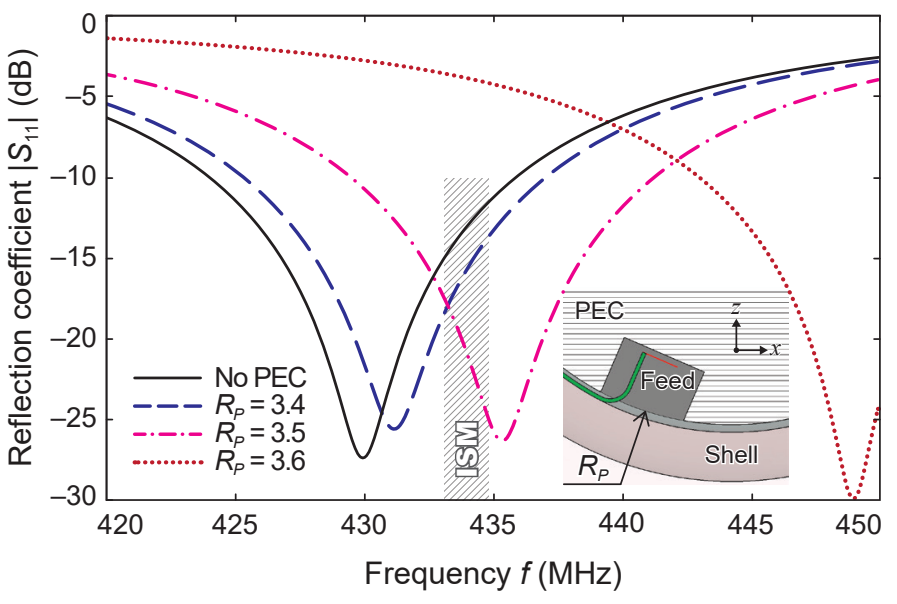

Fig. 8. Effect of capsule inner components on the antenna performance: computed reflection coefficients $\left|S_{11}\right|$ for various radii of a PEC cylinder spanning the full length of the antenna. The inset shows the PEC cylinder $\left(R_{P}=3.6 \mathrm{~mm}\right)$ with a pocket to accommodate the waveguide port.

photolithography. A 16- $\mu$ m-thick polyimide coverlay was applied to both top and bottom layers of the flex. As the relative permittivity of polyimide closely matches that of the epoxy, this configuration does not detune the antenna. Moreover, it protects the design-especially the feed and coplanar $Z_{2}$ section-from accidental mechanical damage while assembling the capsule mockup (Fig. 9b). The flex was designed in such a manner that after folding it there remains at least $0.5-\mathrm{mm}$ gap between the batteries (Fig. 9a) and the coplanar $Z_{2}$ section. In this way, the antenna is not detuned by the inner components (Fig. 8).

To characterize the antenna in terms of its impedance and robustness with a VNA, we used a 100-mm-long semi-rigid coaxial cable terminated with an SMA connector. First, the antenna feed was cut out from the flex and the cable was soldered to a specially designated test pads (Fig. 9a). Second, the white part of the PVC capsule shell (Fig. 9b) was incised to pull the feed through the shell. Third, the flex was folded and inserted into the shell, and the feed was reinforced using the Araldite 2011 epoxy (Fig. 9b). Finally, the capsule was filled with a bi-component epoxy, outgassed, sealed, and cured 


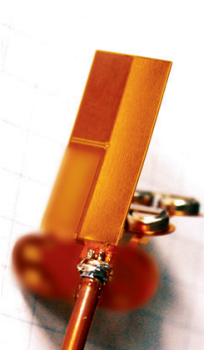

(a)

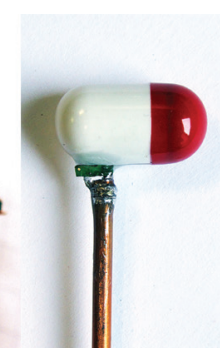

(b)

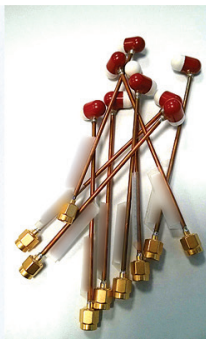

(c)

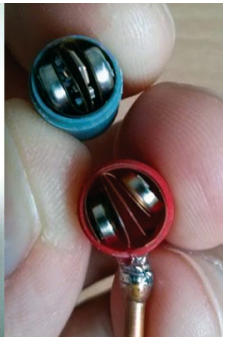

(d)
Fig. 9. Capsule antenna prototype. (a) Planar antenna integrated with the circuitry on the same polyimide substrate (proprietary circuitry blurred) and connected to a semi-rigid coaxial cable for measurements. (b) Final capsule mockup containing the antenna, circuitry, and filled with epoxy resin. (c) Nine prototypes were manufactured to ensure reproducibility. (d) Mockup and the final device without caps showing the alignment of circuitry.

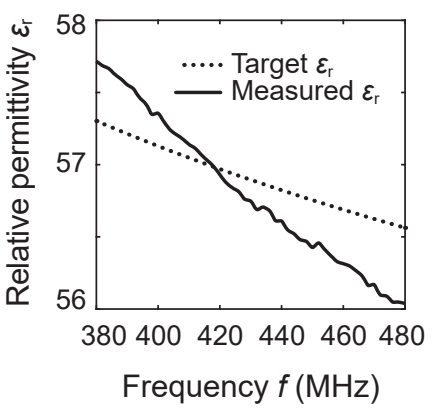

(a)

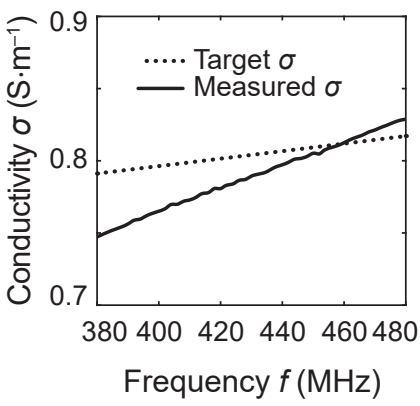

(b)
Fig. 10. Measured and target EM properties (at $25 \pm 0.5^{\circ} \mathrm{C}$ ) of the muscleequivalent liquid phantom used for the antenna measurements. (a) Relative permittivity $\varepsilon_{r}$. (b) Conductivity $\sigma$.

for 24 hours. Nine prototypes were manufactured to ensure reproducibility (Fig. 9c).

The capsule antennas were characterized in terms of $\left|S_{11}\right|$ robustness in three media: a muscle-equivalent liquid phantom, pure water, and air. The radiation performance was characterized in a muscle-equivalent phantom following the methodology given in [21]. To achieve the target EM properties of the muscle-equivalent phantom $\left(\varepsilon_{r}=56.9, \sigma=0.81 \mathrm{~S} \cdot \mathrm{m}^{-1}\right.$ at $434 \mathrm{MHz}$ ), we used a water-sucrose-sodium chloride formula (see details in [21]). Sucrose $\left(\mathrm{C}_{12} \mathrm{H}_{22} \mathrm{O}_{11}\right.$, Sigma-Aldrich "BioXtra Sucrose," S7903, $\geq 99.5 \%$ ) reduced the permittivity $\varepsilon_{r}$ of pure water, and sodium chloride $(\mathrm{NaCl}$, Sigma-Aldrich "BioXtra Sodium Chloride," S7653, $\geq$ 99.5\%) increased the conductivity $\sigma$. The phantom was prepared and used afterwards for the antenna measurements in a temperaturecontrolled environment $\left(25 \pm 0.5^{\circ} \mathrm{C}\right)$. The weighting precision was $\pm 0.01 \%$ (Kern EMB 2000-2). To validate the EM properties of the obtained phantoms, we used the SPEAG DAK kit with DAK-12 probe [42]. Fig. 10 shows the measured EM properties of the phantom compared to the target ones. Considering the ultra-robust characteristics of the antenna (Fig. 5), the achieved EM properties are sufficienctly accurate. Since only the layer of phantom directly adjacent to the capsule affects the antenna impedance, there is no need to replicate the phantom shape exactly given it has a similar volume to the simulated one. Therefore, for the impedance

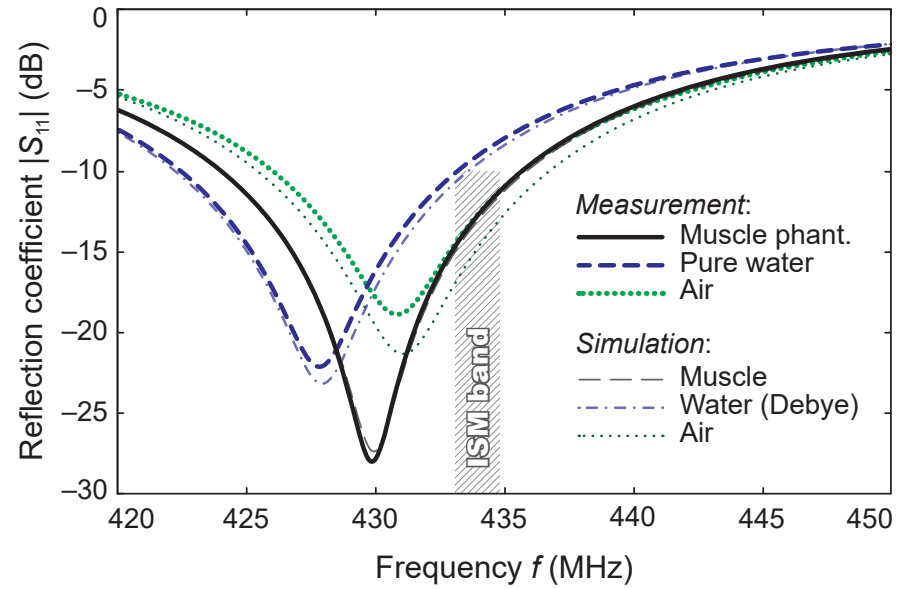

Fig. 11. Measured and computed reflection coefficients $\left|S_{11}\right|$ of the proposed antenna in three media.

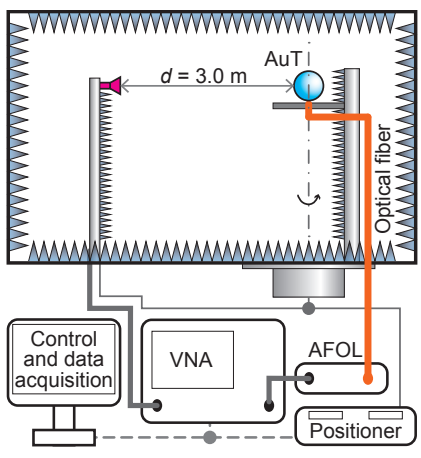

(a)

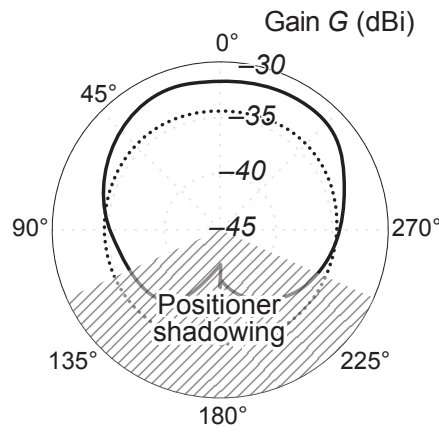

(b)
Fig. 12. (a) Outline of the far-field measurement of the proposed antenna in an anechoic chamber. (b) Measured (-) and computed (...) azimuthal copol radiation patterns of the AuT centered in a $\varnothing 100-\mathrm{mm}$ spherical phantom with muscle-equivalent EM properties.

measurements, the muscle-equivalent phantom and pure water were contained in a $90 \mathrm{~mm} \times \varnothing 90 \mathrm{~mm}$ cylindrical vessel for convenience. The radiation measurements employed a $\varnothing 100$ $\mathrm{mm}$ spherical glass jar to contain the liquid phantom. As unbalanced feeds affect strongly the measurement accuracy of ESAs [43], we used a methodology proposed by Merli et al. [13]. This approach consists in insulating the feed from a liquid phantom by a layer of air. For that, we surrounded the feeding cable by an airtight $\varnothing 10$-mm polyamide tube.

We used the Agilent PNA-X VNA to characterize the reflection coefficient of the antenna in different media. As the VNA was calibrated in the reference plane of the SMA connector, the cable influence on impedance was deembedded during postprocessing in CST Design Studio. Fig. 11 shows the reflection coefficients $\left|S_{11}\right|$ of the fabricated antenna prototype as measured in muscle-equivalent phantom, air, and pure water. The results in phantom and pure water are in excellent agreement with the simulations. A $2.5-\mathrm{dB}$ difference for $\left|S_{11}\right|$ in air can be attributed to the fact that the antenna couples more to the cable in this configuration (the technique that we used allows us decoupling the antenna only in lossy high-permittivity media).

To characterize the radiation performance, this study applied 
TABLE II

Comparison of Designs, Operating Frequencies, Supported Environments (in Addition to Muscle), and Radiation Performances in the Given Phantoms of the CAPSUle Antennas RePorted in Literature

\begin{tabular}{clcrcrl}
\hline Ref. & Antenna type & Capsule $(\mathrm{mm})$ & $f_{0}(\mathrm{MHz})$ & Air, Fat, GI & $G(\mathrm{dBi})$ & Phantom, shape, size $(\mathrm{mm})$ \\
\hline- & Slot-patch & $17.7 \times \varnothing 8.9$ & 434 & All & -34 & Muscle, sphere, $\varnothing 100$ \\
{$[12]$} & Helix & $30 \times \varnothing 10$ & 434 & GI & -41 & Muscle, cube, $190^{3}$ \\
& & 403 & GI & -29 & Muscle, cylinder ${ }^{*}, 110 \times \varnothing 80$ \\
{$[13]$} & Multilayer spiral & $32 \times \varnothing 10$ & 2450 & & -19 & \\
& & 403 & GI & -30 & \\
& & 915 & & -25 & Stomach, anatomical (Gustav $)^{\ddagger}$ \\
{$[15]$} & Inverted-F & $32 \times \varnothing 10$ & & & -23 & \\
& & & & & \\
{$[17]$} & Meander-line & $26 \times \varnothing 11$ & 434 & GI & -32 & Mus., ellip. cyl., $\varnothing 360 \times \varnothing 240 \times 100$ \\
{$[18]$} & Loop & $26 \times \varnothing 11$ & 434 & GI & -31 & Muscle, cube, $100^{3}$ \\
{$[19]$} & Loop & $26 \times \varnothing 11$ & 434 & GI & -28 & Muscle, cylinder, $80 \times \varnothing 180$ \\
{$[21]$} & Microstrip & $17 \times \varnothing 7$ & 434 & Fat, GI & -22 & Muscle, sphere, $\varnothing 100$ \\
\hline
\end{tabular}

The capsule is off-centered, distance to the surface $\approx 10 \mathrm{~mm}$.

The capsule is off-centered, distance to the surface is not given.

The distance to the surface is $5.5 \mathrm{~cm}$.

a previously proposed approach [21] that uses far-field direct illumination of the AuT placed in a fully-anechoic chamber and fed with an electro-optical converter (enprobe LFA-3 [45]). Fig. 12a outlines the approach. The AuT is placed at the distance $d=3 \mathrm{~m}$ from the measurement horn fulfilling the far-field criterion $d \gg 2 \lambda$. We measured the radiation in the azimuth plane (elevation $\varphi=0^{\circ}$ ) for a co-polarization component. To derive the realized gain from the measured data, we used the gain substitution technique. Specifically, a reference antenna of a known gain (ETS-Lindgren openboundary quad-ridged horn $3164-06$ [46], $G_{434 \mathrm{MHz}}=4.5 \mathrm{dBi}$ ) substituted the AuT. The measured gain of the reference antenna was used to calibrate the AuT results.

Fig. 12b shows the far-field characterization results. The maximum measured gain $G=-31.7 \mathrm{dBi}$. The radiation pattern and the gain are consistent with the simulated ones. Note the degeneration of backward radiation for both frequency bands. This effect is due to the shadowing effect of the positioner that was described in [21].

\section{DisCUSSION}

The proposed capsule antenna remains well-matched in both air and body tissues, which is, to the best of our knowledge, the first of its kind. The achieved characteristics, however, come at a price. The proposed design requires sacrificing the radiation efficiency due to increased current symmetry and high waveimpedance contrast between the capsule environment and tissues. However, the radiation performance of the antenna stays comparable with counterparts [44] (Table II), but it is less efficient than the hypothetical robust antennas using ceramic materials with $\varepsilon_{r} \geq 10$ (e.g. [21]). The proposed antenna gives a sufficient transmission range of about 2-3 m surrounding a human body when ingested (using a commercial chip antenna with $G=-3 \mathrm{dBi}$ integrated into the off-body receiver).

Note that it is theoretically possible to achieve similar robustness using adaptive matching circuits. However, in practice, these circuits require active components that increase the system complexity and power consumption. Ensuring the robustness on the antenna level allows one using less voluminous and more power-efficient passive circuits. Theoretically, wideband antennas can achieve such robustness too, but, taking into account that we deal with ESAs, it would require introducing significant losses in antenna and capsule materials.

The antenna has been simulated and tested in homogeneous environments. However, human/animal bodies are highly heterogeneous and anisotropic. Whereas isotropy can be safely assumed at RF frequencies [47], heterogeneity significantly affects the radiation of in-body antennas [9]. Therefore, provided values of the antenna gain are valid only for the reference purposes (using a "standard" spherical phantom allows for comparing the antenna with counterparts [39]). Accurate evaluation of antenna radiation for any particular scenario requires a statistical-EM approach [48] using anatomical phantoms.

Although we did not perform impedance measurements in cadaveric tissues or in vivo, the considered range of EM properties $\left(\varepsilon_{r} \in[1 . .80], \sigma \in[0 . .2 .4] \mathrm{S} \cdot \mathrm{m}^{-1}\right)$ equivalently spans all possible macroscopic properties encountered among mammalian tissues [10].

\section{CONCLUSION}

We proposed a biotelemetry capsule platform that can be used for arbitrary in-body applications independently of surrounding tissue. Ultra-robust impedance characteristics of the antenna were achieved for the first time. The antenna is integrated into the PCB of the device along with a sensor (thermocouple), a microcontroller (Si 10XX family), and a power source (button-cell batteries, Fig. 9d). The antenna and the PCB were realized within the same technological process.

Implementation of such biotelemetry capsule (e.g. BodyCap e-Celsuis [11]) can be used, for instance, as an ingestible for humans and as an implantable for a wide range of animals: from rodents to cattle. Roussey et al. [49] reported an intracorporal temperature telemetry using a realization of the proposed technology. The proposed design (both in planar and 
conformal realizations) can also be used in active implantable medical devices featuring therapeutic actuation as well as applied to other non-medical fields where high robustness to environment is essential.

\section{ACKNOWLEDGMENT}

The authors thank Fabrice Verjus as well as PierreAlexandre Chapon and Estelle Blond from BodyCap for their support and fruitful discussions.

\section{REFERENCES}

[1] A. Kiourti and K. S. Nikita, "A review of in-body biotelemetry devices: implantables, ingestibles, and injectables," IEEE Trans. Biomed. Eng., vol. 64, no. 7, pp. 1422-1430, Jul. 2017.

[2] A. K. RamRakhyani, S. Mirabbasi, and M. Chiao, "Design and optimization of resonance-based efficient wireless power delivery systems for biomedical implants," IEEE Trans. Biomed. Circuits Syst., vol. 5, no. 1, pp. 48-63, Feb. 2011.

[3] S. Bakogianni and S. Koulouridis, "On the design of miniature MedRadio implantable antennas," IEEE Trans. Antennas Propag., vol. 65, no. 7, pp. 3447-3455, Jul. 2017.

[4] A. S. Y. Poon, "Miniaturized Biomedical Implantable Devices," in Implantable Bioelectronics, Weinheim, Germany: Wiley-VCH, 2014, pp. $45-64$.

[5] M. P. Soares dos Santos et al., "New cosurface capacitive stimulators for the development of active osseointegrative implantable devices," Sci. Rep., vol. 6, p. 30231, Jul. 2016.

[6] G. Bonmassar, S. W. Lee, D. K. Freeman, M. Polasek, S. I. Fried, and J. T. Gale, "Microscopic magnetic stimulation of neural tissue," Nat. Commun., vol. 3, p. 921, Jun. 2012.

[7] R. Morais et al., "An activation circuit for battery-powered biomedical implantable systems," Sens. Actuator A-Phys., vol. 156, no. 1, pp. 229236, Nov. 2009.

[8] L. Xu, M. Q.-H. Meng, and Y. Chan, "Effects of dielectric parameters of human body on radiation characteristics of ingestible wireless device at operating frequency of $430 \mathrm{MHz}$," IEEE Trans. Biomed. Eng., vol. 56, no. 8, pp. 2083-2094, Aug. 2009.

[9] D. Nikolayev, M. Zhadobov, P. Karban, and R. Sauleau, "Electromagnetic radiation efficiency of body-implanted devices," Phys. Rev. Appl., vol. 9, no. 2, pp. 024033, Feb. 2018.

[10] S. Gabriel, R. W. Lau, and C. Gabriel, "The dielectric properties of biological tissues: II. Measurements in the frequency range $10 \mathrm{~Hz}$ to 20 GHz," Phys. Med. Biol., vol. 41, pp. 2251-2269, Nov. 1996.

[11] BodyCap Medical. e-Celsius. Accessed: Feb. 20, 2018. [Online]. Available: http://www.bodycap-medical.com

[12] J. Faerber et al., "In vivo characterization of a wireless telemetry module for a capsule endoscopy system utilizing a conformal antenna," IEEE Trans. Biomed. Circuits Syst., vol. 12, no. 1, pp. 95-105, Feb. 2017.

[13] F. Merli, L. Bolomey, J. Zurcher, G. Corradini, E. Meurville, and A. K. Skrivervik, "Design, realization and measurements of a miniature antenna for implantable wireless communication systems," IEEE Trans. Antennas Propag., vol. 59, no. 10, pp. 3544-3555, Oct. 2011.

[14] A. Kiourti, J. R. Costa, C. A. Fernandes, A. G. Santiago, and K. S. Nikita, "Miniature implantable antennas for biomedical telemetry: from simulation to realization," IEEE Trans. Biomed. Eng., vol. 59, no. 11, pp. 3140-3147, Nov. 2012.

[15] Z. Bao, Y. X. Guo, and R. Mittra, "Single-layer dual-/tri-band invertedF antennas for conformal capsule type of applications," IEEE Trans. Antennas Propag., vol. 65, no. 12, pp. 7257-7265, Sep. 2017.

[16] Y. Peng, K. Saito, and K. Ito, "Antenna design for impulse-radiobased wireless capsule endoscope communication systems," IEEE Trans. Antennas Propag., vol. 66, no. 10, pp. 5031-5042, Oct. 2018.

[17] J. Wang, M. Leach, E. G. Lim, Z. Wang, R. Pei, and Y. Huang, "An implantable and conformal antenna for wireless capsule endoscopy," IEEE Antenn. Wireless Propag. Lett., vol. 17, no. 7, pp. 1153-1157, Jul. 2018.

[18] W. Lei and Y. Guo, "Design of a dual-polarized wideband conformal loop antenna for capsule endoscopy systems," IEEE Trans. Antennas Propag., vol. 66, no. 11, pp. 5706-5715, Nov. 2018.

[19] M. M. Suzan, K. Haneda, C. Icheln, A. Khatun, and K. Takizawa, "An ultrawideband conformal loop antenna for ingestible capsule endoscope system," in Proc. $10^{\text {th }}$ Eur. Conf. on Antennas and Propagation (EuCAP 2016), Davos, Switzerland, 2016, pp. 1-5.
[20] M. K. Magill, G. A. Conway, and W. G. Scanlon, "Tissue-independent implantable antenna for in-body communications at $2.36-2.5 \mathrm{GHz}$," IEEE Trans. Antennas Propag., vol. 65, no. 9, pp. 4406-4417, Sep. 2017.

[21] D. Nikolayev, M. Zhadobov, L. Le Coq, P. Karban, and R. Sauleau, "Robust ultra-miniature capsule antenna for ingestible and implantable applications," IEEE Trans. Antennas Propag., vol. 65, no. 11, pp. 61076119, Nov. 2017

[22] W. G. Scanlon, B. Burns, and N. E. Evans, "Radiowave propagation from a tissue-implanted source at $418 \mathrm{MHz}$ and $916.5 \mathrm{MHz}$," IEEE Trans. Biomed. Eng., vol. 47, no. 4, pp. 527-534, Apr. 2000.

[23] L. C. Chirwa, P. A. Hammond, S. Roy, and D. R. S. Cumming, "Electromagnetic radiation from ingested sources in the human intestine between $150 \mathrm{MHz}$ and $1.2 \mathrm{GHz}$," IEEE Trans. Biomed. Eng., vol. 50, no. 4, pp. 484-492, Apr. 2003.

[24] International Telecommunication Union. ITU Radio Regulations (article 5), footnotes 5.138, 5.150, and 5.280. Accessed: Feb. 20, 2018. [Online]. Available: https://www.itu.int/net/ITU-R/terrestrial/ faq/index.html\#g013

[25] Federal Communications Commission. Medical Device Radiocommunications Service (MedRadio). Accessed: Feb. 20, 2018. [Online]. Available: https://www.fcc.gov/medical-device-radiocommunicationsservice-medradio

[26] F. Merli, B. Fuchs, J. R. Mosig, and A. K. Skrivervik, "The effect of insulating layers on the performance of implanted antennas," IEEE Trans. Antennas Propag., vol. 59, no. 1, pp. 21-31, Jan. 2011.

[27] D. Nikolayev, M. Zhadobov, P. Karban, and R. Sauleau, "Increasing the radiation efficiency and matching stability of in-body capsule antennas," in Proc. $10^{\text {th }}$ Eur. Conf. on Antennas and Propagation (EuCAP 2016), Davos, Switzerland, 2016, pp. 1-5.

[28] C. Pfeiffer, "Fundamental efficiency limits for small metallic antennas," IEEE Trans. Antennas Propag., vol. 65, no. 4, pp. 1642-1650, Apr. 2017.

[29] A. Karlsson, "Physical limitations of antennas in a lossy medium," IEEE Trans. Antennas Propag., vol. 52, no. 8, pp. 2027-2033, Aug. 2004.

[30] R. Garg, P. Bhartia, I. Bahl, and A. Ittipiboon, Microstrip Antenna Design Handbook. Norwood, MA: Artech House, 2001.

[31] DuPont. Kapton Polyimide Film. Accessed: Nov. 20, 2018. [Online]. Avaliable: http://www.dupont.com/products-and-services/membranesfilms/polyimide-films/brands/kapton-polyimide-film.html

[32] M. Sagawa, M. Makimoto, and S. Yamashita, "Geometrical structures and fundamental characteristics of microwave stepped-impedance resonators," IEEE Trans. Microw. Theory Tech., vol. 45, no. 7, pp. 10781085, Jul. 1997.

[33] D. M. Pozar, Microwave Engineering, $4^{\text {th }}$ ed. Hoboken, NJ: Wiley, 2012.

[34] Y. Mahe, A. Chousseaud, M. Brunet, and B. Froppier, "New flexible medical compact antenna: design and analysis," Int. J. Antennas Propag., vol. 2012, May 2012, Art. no. 837230.

[35] D. Nikolayev, Z. Kubik, P. Karban, and J. Skala, "Impedance analysis of transmission line cells for EMC applications using Agros2D," Appl. Math. Comput., vol. 289, pp. 381-387, 2016.

[36] D. Nikolayev, M. Zhadobov, P. Karban, and R. Sauleau, "434 MHz ISM band antenna for in-body biotelemetry capsules," in Proc. $11^{\text {th }}$ Eur. Conf. on Antennas and Propagation (EuCAP 2017), Paris, France, 2017, pp. $1035-1038$.

[37] P. A. Chapon, A. Gauthier, J. Bulla, and S. Moussay, "Calibration and performance assessment of a temperature sensor prototype using a 1-point calibration procedure," Rev. Sci. Instrum., vol. 83, no. 11, p. 114907, Nov. 2012.

[38] Computer Simulation Technology AG. CST Microwave Studio. Accessed: Feb. 20, 2018. [Online]. Available: http://www.cst.com

[39] D. Nikolayev, M. Zhadobov, and R. Sauleau, "Impact of tissue electromagnetic properties on radiation performance of in-body antennas," IEEE Antenn. Wireless Propag. Lett., vol. 17, no. 8, pp. 1440-1444, Jun. 2018.

[40] D. Sinha and G. A. J. Amaratunga, "Electromagnetic radiation under explicit symmetry breaking," Phys. Rev. Lett., vol. 114, no. 14, p. 147701, Apr. 2015.

[41] C. A. Balanis, Antenna Theory: Analysis and Design, $4^{\text {th }}$ ed. Hoboken, NJ: John Wiley \& Sons, 2016.

[42] Schmid \& Partner Engineering AG. Dielectric Assessment Kit. Accessed: Feb. 20, 2018. [Online]. Available: http://www.speag.com/ products/dak/dielectric-measurements

[43] L. Huitema, C. Delaveaud, and R. D'Errico, "Impedance and radiation measurement methodology for ultra miniature antennas," IEEE Trans. Antennas Propag., vol. 62, no. 7, pp. 3463-3473, Jul. 2014.

[44] D. Nikolayev, M. Zhadobov, P. Karban, and R. Sauleau, "Conformal antennas for miniature in-body devices: the quest to improve radiation performance," Radio Sci. Bull., vol. 2017, no. 363, pp. 52-64, Dec. 2017. 
[45] enprobe GmbH. LFA-3 Analog Fiber Optic Link. Accessed: Feb. 20, 2018. [Online]. Available: http://www.enprobe.de/products_FOLinks.htm

[46] ETS-Lindgren. 3164-06 Quad-Ridged Horn. Accessed: Feb. 20, 2018. [Online]. Available: http://www.ets-lindgren.com/3164-06

[47] W. D. Hurt, J. M. Ziriax, and P. A. Mason, "Variability in EMF permittivity values: implications for SAR calculations," IEEE Trans. Biomed. Eng., vol. 47, no. 3, pp. 396-401, Mar. 2000.

[48] R. Holland, Statistical Electromagnetics, $1^{\text {st }}$ ed. Philadelphia, PA: CRC Press, 1999.

[49] G. Roussey, M. Gruet, F. Vercruyssen, J. Louis, J.-M. Vallier, and T. Bernard, "Interactions between perceived exertion and thermal perception in the heat in endurance athletes," J. Therm. Biol., vol. 76, pp. 68-76, Aug. 2018.

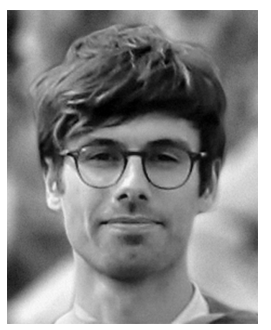

Denys Nikolayev (S'14-M'17) received the B.S. (cum laude) and M.S. (cum laude) degrees in electronics and telecommunications from Lviv Polytechnic National University, Lviv, Ukraine, in 2008, and the joint Ph.D. degrees in electronics from the Institute of Electronics and Telecommunication of Rennes (IETR), France and in electrical engineering from the University of West Bohemia in Pilsen, Czechia in 2017.

His research interests include antennas and propagation for body-centric networks, neural interfaces, bioelectromagnetics, and numerical methods in electromagnetics. He authored one book chapter, nine journal papers, 16 publications in international conference proceedings, and holds three patents.

Dr. Nikolayev is a member of the Institute of Electrical and Electronics Engineers (IEEE), the Bioelectromagnetics Society (BEMS), and the European Bioelectromagnetics Association (EBEA). He was awarded by the Foundation of Rennes 1 for his Ph.D. and was a laureate of the Eiffel Excellence Doctoral Grant (2015/2016). He received the Best Paper Award at the URSI-France 2017 Workshop and the Poster Award at the BioEM'2015.

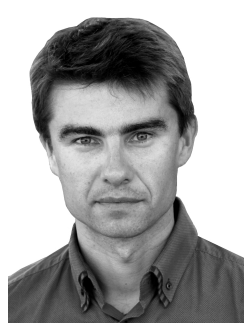

Maxim Zhadobov (S'05-M'07-SM'15) received the M.S. degree in electromagnetics from the University of Nizhny Novgorod, Nizhny Novgorod, Russia, in 2003, and the Ph.D. and Habilitation à Diriger des Recherches (HDR) degrees from the Institute of Electronics and Telecommunications of Rennes (IETR), University of Rennes 1, Rennes, France, in 2006 and 2016, respectively.

He was a Post-Doctoral Researcher with the Center for Biomedical Physics, Temple University, Philadelphia, PA, USA, until 2008, and then joined the French National Center for Scientific Research (CNRS). He is currently the principal investigator in biomedical electromagnetics with the IETR/CNRS and head of the WAVES team of the IETR. He co-authored five book chapters and over 54 research papers in peer-reviewed international journals. He has been involved in over 20 research projects at the National and European levels. His current scientific interests and research activities are in the field of innovative biomedical applications of electromagnetic fields and associated technologies.

Dr. Zhadobov was a session organizer and/or a technical committee member at several international conferences, including IEEE iWEM 2017, BodyNets 2016, MobiHealth (since 2015), IMWS-Bio 2014, and PIERS 2013. Since 2017, he has been Engineering/Physical Sciences Chair of the EBEA Council. He was awarded by the CNRS Medal in 2018, and received EBEA Award for Excellence in Bioelectromagnetics 2015 and the Brittany's Young Scientist Award 2010. Since 2010, Ph.D. students he supervised received seven national scientific awards and four awards from the Bioelectromagnetics and the IEEE Antennas and Propagation Societies.

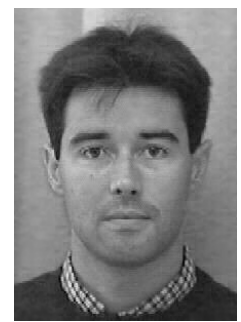

Ronan Sauleau (M'04-SM'06-F'18) graduated in electrical engineering and radio communications from the Institut National des Sciences Appliquées, Rennes, France, in 1995. He received the Agrégation degree from the Ecole Normale Supérieure de Cachan, France, in 1996, and the Doctoral degree in signal processing and telecommunications and the "Habilitation à Diriger des Recherches" degree, both from the University of Rennes 1, France, in 1999 and 2005, respectively.

He was an Assistant Professor and Associate Professor at the University of Rennes 1, between September 2000 and November 2005, and between December 2005 and October 2009, respectively. He has been appointed as a full Professor in the same University since November 2009. His current research fields are numerical modeling (mainly FDTD), millimeter-wave printed and reconfigurable (MEMS) antennas, substrate integrated waveguide antennas, lens-based focusing devices, periodic and non-periodic structures (electromagnetic bandgap materials, metamaterials, reflectarrays, and transmitarrays) and biological effects of millimeter waves. $\mathrm{He}$ has been involved in more than 60 research projects at the national and European levels and has co-supervised 23 post-doctoral fellows, $44 \mathrm{PhD}$ students and 50 master students.

$\mathrm{He}$ has received 15 patents and is the author or coauthor of more than 215 journal papers and 470 publications in international conferences and workshops. He has shared the responsibility of the research activities on antennas at IETR in 2010 and 2011. He was co-director of the research Department 'Antenna and Microwave Devices' at IETR and deputy director of IETR between 2012 and 2016. He is now director of IETR. Prof. Sauleau received the 2004 ISAP Conference Young Researcher Scientist Fellowship (Japan) and the first Young Researcher Prize in Brittany, France, in 2001 for his research work on gain-enhanced Fabry-Perot antennas. In September 2007, he was elevated to Junior member of the "Institut Universitaire de France". He was awarded the Bronze medal by CNRS in 2008. He was the co-recipient of several international conference awards with some of his students (Int. Sch. of BioEM 2005, BEMS'2006, MRRS'2008, E-MRS'2011, BEMS'2011, IMS'2012, Antem'2012, BioEM'2015). He served as a guest editor for the IEEE Antennas Propogat. Special Issue on "Antennas and Propagation at mm and sub $\mathrm{mm}$ waves". He served as a national delegate for COST VISTA. Since 2013 he is national delegate for EurAAP, and is a member of the board of directors of EurAAP. 